\title{
Electrical resistivity of additively manufactured AlSi10Mg for use in electric motors
}

\author{
Cassidy Silbernagel ${ }^{{ }^{*}}$, lan Ashcroft ${ }^{a}$, Phill Dickens ${ }^{a}$, Michael Galea ${ }^{b, c}$ \\ a Centre for Additive Manufacturing (CfAM), Faculty of Engineering, University of Nottingham, Nottingham NG7 2GW, UK \\ ${ }^{b}$ Power Electronics, Machines and Control Group, Faculty of Engineering, University of Nottingham, Nottingham NG7 2RD, UK \\ c Power Electronics, Machines and Control Group, University of Nottingham, Ningbo, China, Ningbo 315100, China \\ *Corresponding author Cassidy.Silbernagel@nottingham.ac.uk
}

\section{Abstract}

Additive manufacturing (AM) opens up a design freedom beyond the limits of traditional manufacturing techniques. Electrical windings created through AM could lead to more powerful and compact electric motors, but only if the electrical properties of the AM printed part can be shown to be similar to conventionally manufactured systems. Until now, no study has reported on the suitability of AM parts for electrical applications as there are few appropriate materials available to AM for this purpose. AISi10Mg is a relatively good electrical conductor that does not have the same reported issues associated with processing pure aluminium or copper via selective laser melting (SLM). Here, experiments were conducted to test the effects of geometry and heat treatments on the resistivity of AISi10Mg processed by SLM. It was found that post heat treatments resulted in a resistivity that was $33 \%$ lower than the as-built material. The heat treatment also eliminated variance in the resistivity of as-built parts due to initial build orientation. By conducting these tests, it was found that, with this material, there is no penalty in terms of higher resistivity for using AM in electrical applications, thus allowing more design freedom in future electrical applications.

\section{Keywords:}

- electrical resistivity;

- electrical conductivity;

- selective laser melting;

- additive manufacturing;

- 3D printing;

- aluminum alloy;

\section{Highlights:}

- 3D printed AISi10Mg can be used in electrical applications once heat treated

- Electrical resistivity values once heat treated are comparable to cast alloy values

- Resistivity of as-built AISi10Mg increases by $27 \%$ depending on build orientation

- Heat treatment can reduce as-built resistivity by $33 \%$

\section{Graphical abstract:}

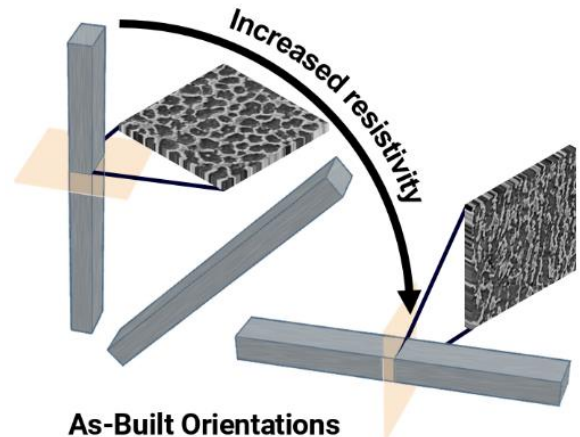

As-Built Orientations

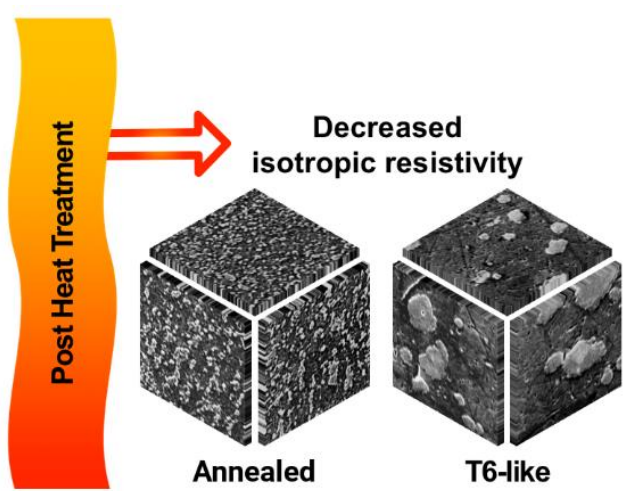

T6-like 


\section{Introduction}

Additive manufacturing (AM) has been called many different names over the past 30 years. From Rapid Prototyping (RP)[1] and Rapid Tooling[2] to Rapid Manufacturing (RM)[1] and 3D Printing (3DP)[3]. It is creating opportunities to design parts that could not otherwise be easily made using traditional subtractive (e.g. CNC machines) or formative (e.g. metal casting) techniques. AM provides a new tool for designers, who can then follow rules to Design for Additive Manufacturing (DfAM)[4] and create optimised AM parts. This new design freedom can reduce part counts, create complex internal geometry, and remove excess material.

The golden age of electric motors was the mid to late 1800 s where rapid advances in design and manufacturing occurred. More recently, electrical machines have enjoyed several advances related to new types, topologies, and operation[5]. Electrical machines continue to improve performance in terms of power density, efficiency and reliability. Yet, modern electric motors still depend on conventional manufacturing methods that go back to the $1960 \mathrm{~s}$ and 70s. These conventional methods have a negative effect on repeatability and reliability. In aerospace, this is a major bottleneck preventing electrical machines from finding a much more important role in the sector $[6,7]$.

Advanced manufacturing of electrical machines has been explored[8-10], including, recently, AM[11-13]. Yet, they have not used the redesign techniques seen in aerospace, biomedical applications. Antenna design has also been advancing rapidly through the adoption of AM with many new designs[14-16] and patents[17] being published. The benefits of weight reduction have been shown through the use of design optimisation methods[18-20]. Applying DfAM creates a part better suited for AM[21-23]. New families of electrical machines can potentially be created that were impossible to manufacture using traditional methods[24-26]. However, before this can happen, a thorough understanding is needed of how the AM printed materials behave electrically, mechanically, and magnetically $[27,28]$.

A critical component of an electrical machine is its windings, which are usually comprised of a series of coils. The coils are wires made of a conductive material surrounded by a resistive insulation material. The conductive core must have a low electrical resistivity to minimize Joule losses ( $I^{2} R$ loss where $I$ is current and $R$ is resistance) that manifest as heat. Typically materials are copper, silver, gold, or aluminium, see Table 1 . Several attempts to produce such wires with an AM process have been reported[29-31]. But such processes usually create thin films of either silver[32] or copper[33] and cannot create the large 3D coils needed for motors.

\begin{tabular}{rlllll}
\hline Main Element & Description & \multicolumn{3}{l}{ Electrical resistivity $(\mu \Omega-\mathbf{c m})$} & \multicolumn{2}{l}{ Density $\left(\mathbf{g} / \mathrm{cm}^{3}\right)$} \\
\hline Silver & Pure Ag & 1.586 & {$[34]$} & 10.492 & {$[34]$} \\
\hline Copper & Commercially pure Cu & 1.7241 & {$[35]$} & 8.94 & {$[36]$} \\
\hline Gold & Pure Au & 2.192 & {$[34]$} & 19.37 & {$[37]$} \\
\hline Copper & GRCop-84 alloy & 2.45 & {$[38]$} & 8.87 & {$[38]$} \\
\hline Aluminium & Pure Al & 2.6548 & {$[39]$} & 2.688 & {$[37]$} \\
\hline Aluminium & 1350 electrical alloy & 2.82 & {$[40]$} & 2.705 & {$[40]$} \\
\hline Aluminium & AlSi10Mg cast alloy & $4.91,4.26-5.56[41,42]$ & 2.659 & {$[41]$} \\
\hline Copper & Yellow Brass (70\% Cu, 30\% Zn) & 8.85 & {$[36]$} & 8.44 & {$[36]$}
\end{tabular}

Table 1: Electrical resistivity and density of common metals and alloys used in electrical applications at room temperature.

A few powder bed fusion processes have processed these materials. For example, Electron Beam Melting (EBM) with copper has had some electrical measurements reported $[43,44]$. However, in both cases, the method reported does not directly measure resistivity. But rather it back calculates surface conductivity and assumes isotropic properties[45]. Selective laser melting (SLM) has been used with copper[46,47], silver[48], gold[49], aluminium[50]. But few have reported on their electrical properties, and none have reported if these properties were isotropic or not. 
While silver, copper, and gold have a lower resistivity than aluminium, the cost of silver and gold prevent them from being used for anything other than thin film conductors. Pure copper is widely used in electrical applications but has proven difficult to process with AM. Challenges arise in reaching a high density[51], issues of oxidation[43], an inability to process without a high power laser due to its high thermal conductivity[52], high reflectivity[53] and an unstable melt pool[46]. Pure aluminium has similar AM processing issues and as a result, mainly alloys have been processed. However, recently relatively pure aluminium has been printed[54], achieving a density of $99.5 \%$. An advantage that aluminium has over copper is that while it has approximately $60 \%$ higher resistivity than copper, it weighs about $30 \%$ less. Aluminium also costs significantly less than copper which has had high fluctuations in price in the past. Thus aluminium can carry more current per kilogram or per dollar than copper. This gives it an advantage in applications where weight or cost is an important design requirement such as in aerospace[55], automotive[56], or in high-frequency applications[57].

While pure aluminium has a better conductivity than any of its alloys it is too soft to be processed in the manufacture of electric wires. Thus the 1350 alloy has been developed for electrical purposes. It is $99.5 \%$ pure aluminium and has $61.2 \%$ the conductivity of copper[40]. Commercially pure copper is rated at $100 \%$ according to the International Annealed Copper Standard (IACS). However, when pure aluminium is melted and cooled quickly, it shrinks quickly resulting in hot tears and cracking[58]. The casting industry has developed a range of alloys which contain some silicon and magnesium to help counteract this phenomenon while also increasing strength. AISi10Mg is a casting alloy that was adopted early by AM as an easy to process metal powder for SLM[50].

Some have processed this material and reported some electrical conductivity measurements, but each has lacked vital information crucial to adopting it for actual electrical applications. One paper reported on a mix of $1 \%$ by weight carbon nanotubes in AISi10Mg processed with SLM. But the claimed resistivity was in the order of one-tenth of that of pure silver and failed to characterize the base alloy[59]. Another claimed conductivity with respect to various heat treatments[60] but ignored initial build orientation. They also used an indirect measurement method which cannot be used to determine bulk properties. Another paper compared a single as-built AISi10Mg sample to one which was annealed[61]. But it also failed to include initial build orientation and used the same indirect measurement method which resulted in values which were $10 \%$ lower than that expected for cast versions of this alloy (Table 1 ).

While this alloy has been studied extensively in AM processes[62,63], there has not been any focus on pure electrical characterization. Rather the focus has been on reporting the microstructure and physical-mechanical properties. Emphasis has been on how to optimise processing parameters $[64,65]$ or heat treatments $[66,67]$. Those who have reported electrical properties have not correlated them to both initial build orientation and heat treatment. As well, only non-contact indirect surface measurement methods have been used which assume isotropic conductivity[45]. While this can be done with cast versions of this alloy which are isotropic, the grain structure and texture of this alloy produced by AM is distinct from that of cast. To design AM parts for electrical applications, the actual AM properties are needed and are not to be assumed to be the same as cast. This paper will examine the electrical resistivity of an AISi10Mg alloy using a four-wire (Kelvin) test method. This method can directly determine bulk electrical properties. This paper will also compare the effect on resistivity of initial build orientation to as-built conditions and heat treatments.

\section{Material and methods}

\subsection{Material and SLM equipment}

An argon gas atomised AISi10Mg metal powder alloy was obtained from LPW

Technology Ltd. (UK) which was spherically shaped with $99.5 \%$ of it in the range of 20 63 microns. It had a chemical composition as seen in Table 2. It was processed on a 
Renishaw plc (UK) AM250 SLM machine which was equipped with a 200 watt (SPI Laser (UK)) redPOWER ytterbium fibre laser with a wavelength of $1070 \mathrm{~nm}( \pm 10 \mathrm{~nm})$ and a spot size of $70 \mu \mathrm{m}$. The base plate heater was set to $80^{\circ} \mathrm{C}$ and maintained throughout the build process. A vacuum and argon purge was used in the build chamber in order to keep oxygen content below 900 parts per million.

\begin{tabular}{cccccccccc}
$\mathbf{A l}$ & $\mathbf{S i}$ & $\mathbf{M g}$ & $\mathbf{F e}$ & $\mathbf{M n}$ & $\mathbf{C u}$ & $\mathbf{P b}$ & $\mathbf{Z n}$ & $\mathbf{T i}$ & $\mathbf{N i}$ \\
\hline 89.13 & 9.71 & 0.408 & 0.501 & 0.061 & 0.051 & 0.043 & 0.040 & 0.021 & 0.015 \\
\multicolumn{7}{l}{ Table 2: Chemical composition in weight } & percentage of the AlSi10Mg alloy powder provided by $L P W$.
\end{tabular}

\subsection{Laser scanning parameters}

Samples were processed using an optimized parameter set of an exposure time of $140 \mu$ s with a point distance of $80 \mu \mathrm{m}$ and a hatch spacing of $130 \mu \mathrm{m}$ resulting in a laser scan speed of $571 \mathrm{~mm} / \mathrm{s}$ [68]. A checkerboard pattern/"island scanning" strategy[69] was used with a field overlap of $10 \mu \mathrm{m}$ and was rotated on each $25 \mu \mathrm{m}$ thick layer. Parts were spaced out on the build plate as shown in Figure 1.

\subsection{Preparation of samples}

Test bars were designed and printed at $6.5 \mathrm{~mm} \times 3.5 \mathrm{~mm} \times 50 \mathrm{~mm}$ so that an expected resistance for each bar would be at least $100 \mu \Omega$. Four test bars were created for each test case. Three initial build orientations (horizontal, 45 degrees, vertical) were tested with three post heat treatments (none/as-built, typical anneal, T6-like heat treat) resulting in 9 test cases and 36 total test bars. The orientation of the bars is classified according to the normal of the cross-section of the bar which also correlates to the direction of the longest edge of the bar.

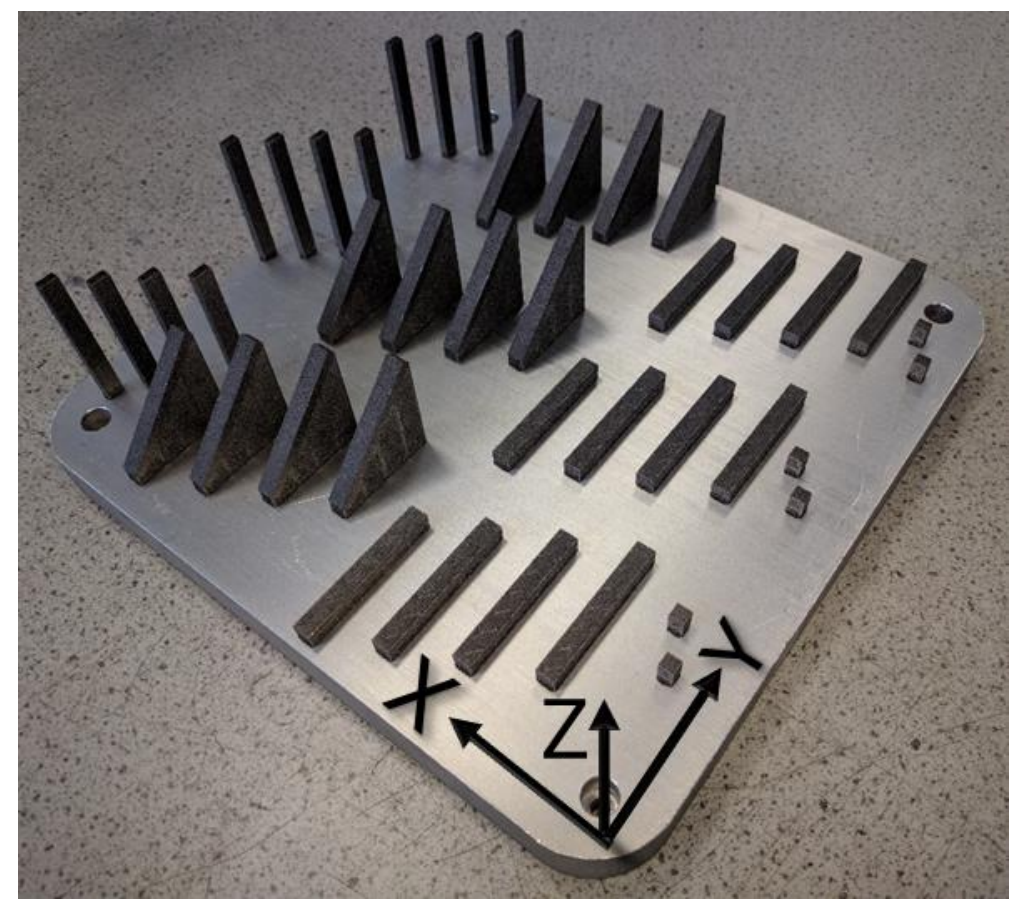

Figure 1: Build plate with electrical test bars printed in vertical, 45-degree, and horizontal initial build orientations along with $5 \mathrm{~mm}$ sample cubes.

Twelve test bars (four of each orientation) and two $5 \mathrm{~mm}$ cubes were removed from the build plate to be tested in an as-built condition. A typical annealing heat treatment[70] was performed on a similar set of samples by placing the test bars and cubes in a preheated furnace set to $300^{\circ} \mathrm{C}$ for $2 \mathrm{hrs}$ and then removing to be air cooled. A T6-like heat treatment[67] was performed on the remaining 12 test bars and $5 \mathrm{~mm}$ cubes by placing them in a preheated furnace set to $520^{\circ} \mathrm{C}$ for $1 \mathrm{hr}$ and then quenching in $20^{\circ} \mathrm{C}$ water. The quenched test specimens were then dried and put into a different preheated furnace, set to $160^{\circ} \mathrm{C}$, for $6 \mathrm{hrs}$ and then removed to be air cooled. 
Test bars were surface ground using 800 grit grinding paper by hand to remove the rough as-built finish. Samples were held using jigs to keep specimens as square as possible and were ground down to remove all surface defects. Samples were individually measured a minimum of three times in five places using callipers to accurately determine the cross-sectional area and length of each. The $5 \mathrm{~mm}$ test cubes were sectioned to expose the $X Y$ plane (top view) and $Y Z$ plane (side view). They were then ground and polished to a mirror finish using established aluminium polishing guidelines. Test cubes were initially imaged and then etched using Keller's reagent for 10 seconds to help reveal the microstructure with further imaging.

\subsection{Characterization of microstructure and properties}

Test cubes were imaged using a Nikon Eclipse LV100ND microscope with a $2560 \times 1920$ pixel colour sensor. These images were used for microstructure analysis. Images were also used to determine density measurements through threshold selection of contrasting areas in the open-source software Fiji (a version of ImageJ software).

Test cubes were also imaged and analysed using an FEI XL-30 field emission scanning electron microscope (SEM) with backscattered electron detection. Images were taken using an acceleration voltage of $20 \mathrm{kV}$ along with an energy dispersive $\mathrm{x}$-ray (EDX) spectrometer for elemental composition analysis which was performed using an Oxford Instruments ISIS system.

Nanoindentation was performed on the test cubes using a Micro Materials Ltd. (UK) NanoTest NTX based machine with a calibrated Berkovich indenter. Fifteen indents were made per sample, spaced $30 \mu \mathrm{m}$ apart with a force of $100 \mathrm{mN}$.

\subsection{Electrical test methodology}

Electrical resistance testing was performed using a Valhalla Scientific Inc. (USA) 4300B digital micro-ohmmeter. This four-wire Kelvin resistance measurement meter was calibrated to within 5\% accuracy by an external vendor and verified internally through tests using precision low-resistivity resistors and current shunts.

Each sample was tested a total of five times, once on its own for a base reading, and then two more times where each instance was a combination of two measurements in succession, being flipped around in the test stand (Figure 2) to reverse the sample. Each reading was clamped using a force of approximately $4000 \mathrm{~N}$ in order to minimize contact resistance between the probes and sample. Measurements were then averaged with the corresponding standard deviations determined.

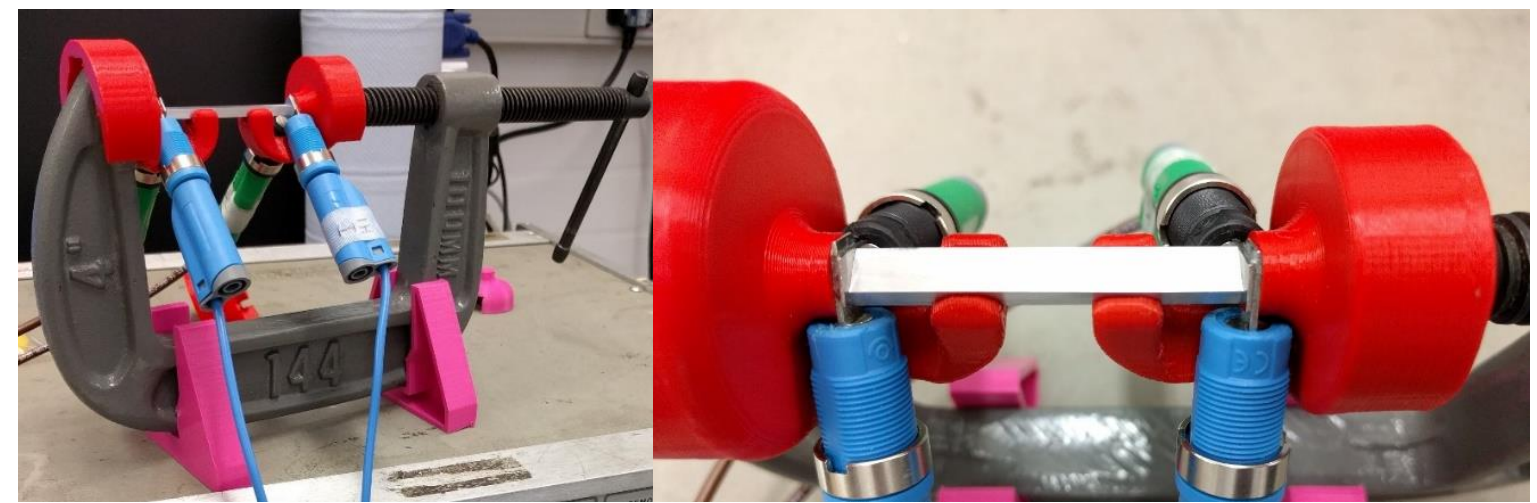

Figure 2: Electrical test jig and setup showing polished aluminium test sample clamped between four-wire Kelvin probes.

Electrical resistivity $(\rho)$ measured in $\mu \Omega$-cm was calculated by $\rho=R A / L$ where $R$ is the measured resistance in $\mu \Omega, A$ is the cross-sectional area of the sample measured in $\mathrm{cm}^{2}$, and $L$ is the length of the sample in $\mathrm{cm}$. 


\section{Results}

\subsection{Microstructure and Density}

Density measurements were taken for all heat treatment states to establish a baseline between samples and examine if a low or highly variable porosity could contribute to variations in resistivity. To establish relative density measurements, the polished $5 \mathrm{~mm}$ test cubes were compared using the microscope and thresholding using computer software. It was found that densities had an average of $99.72 \%$, with only a small variation between all samples, as seen in Table 3 . This suggests that the differences in resistivity of the samples should be due to the microstructure of the alloy and not due to voids from an increased amount of porosity or from large variations in porosity.

\begin{tabular}{rlll}
\hline & As-built & Annealed & T6-like Heat Treatment \\
\hline XY plane (Top) & $99.73 \%$ & $99.76 \%$ & $99.87 \%$ \\
\hline YZ plane (Side) & $99.82 \%$ & $99.30 \%$ & $99.87 \%$
\end{tabular}

Table 3: Relative average densities of $5 \mathrm{~mm}$ test cubes.

To establish the grain and microstructure of the same $5 \mathrm{~mm}$ test cubes, optical micrographs were compared. All images in Figure 3 were taken under the same light and camera settings. Melt pool boundaries can be clearly seen in the as-built samples as elongated ellipses in the $X Y$ (top) plane and as trough-like features in the $Y Z$ (side) plane. Annealed sections still show some of the boundaries of the original melt pools but are fainter and more difficult to see. The T6-like heat treated samples do not show any discernible boundaries and are homogeneous in appearance. This suggests that there is a difference between the samples, and any variances between measured resistivity can be attributed to these observed differences.

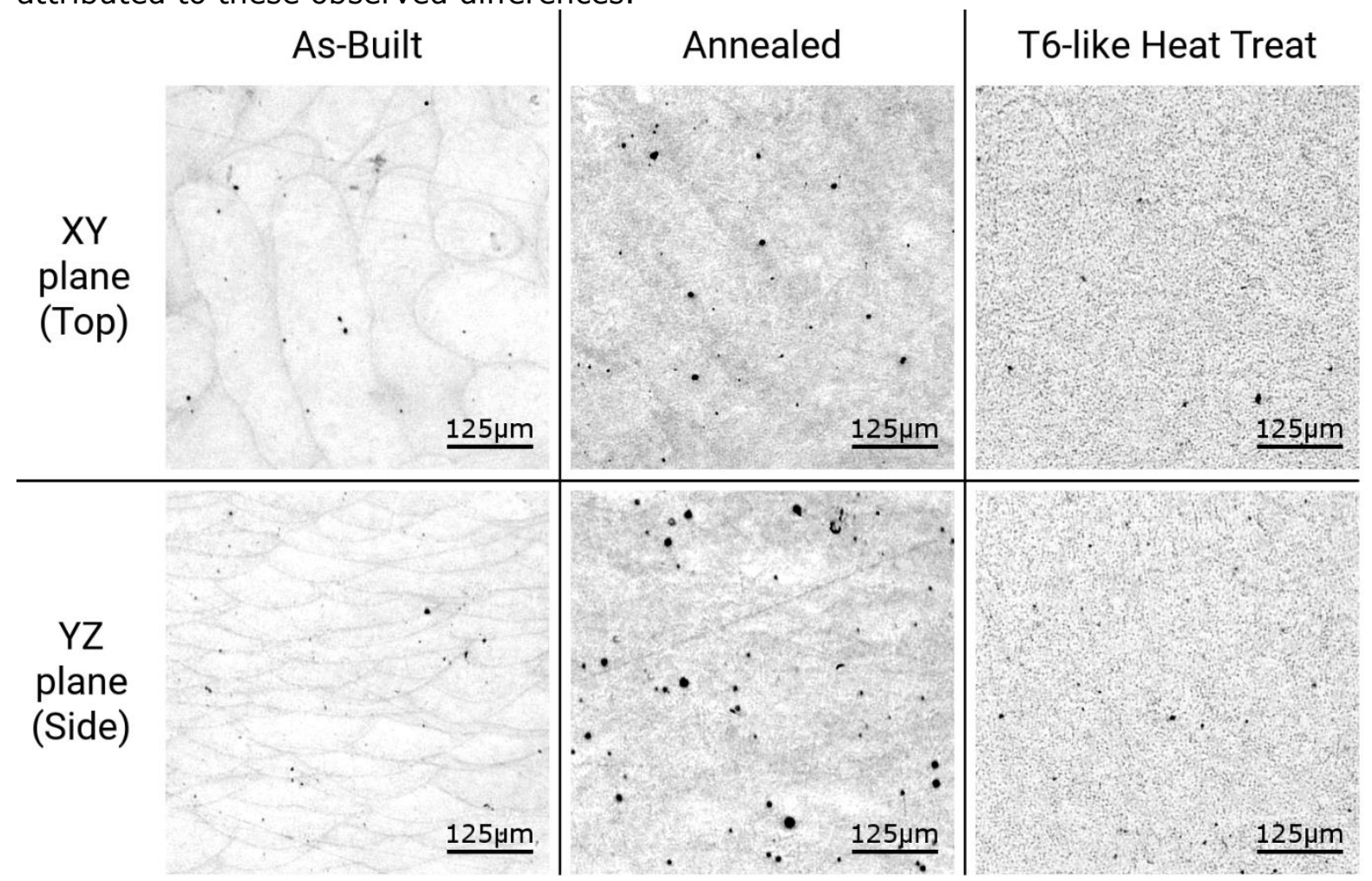

Figure 3: Optical micrographs of the polished $5 \mathrm{~mm}$ test cubes.

To further expose the grain structure the polished cross-sections were etched with Keller's reagent for 10 seconds and then imaged using optical and SEM techniques, as shown in Figure 4 and Figure 5 . The as-built samples show very clear grain boundaries with regions of fine grain structures in the centre of melt pool boundaries, larger grain structures nearing the edge of the melt pool boundary, and varied disrupted structures at 
the edges of the melt pool boundaries, representing a heat affected zone (HAZ)[69]. The annealed sample's microstructure is similar to the as-built, however, the grain structures do not appear to be as clearly defined and are more representative of the HAZ structures seen in the as-built samples. The T6-like heat treated samples show a very different structure, with no clear grain or melt pool boundaries, but showing regions of different sized spheroid structures.

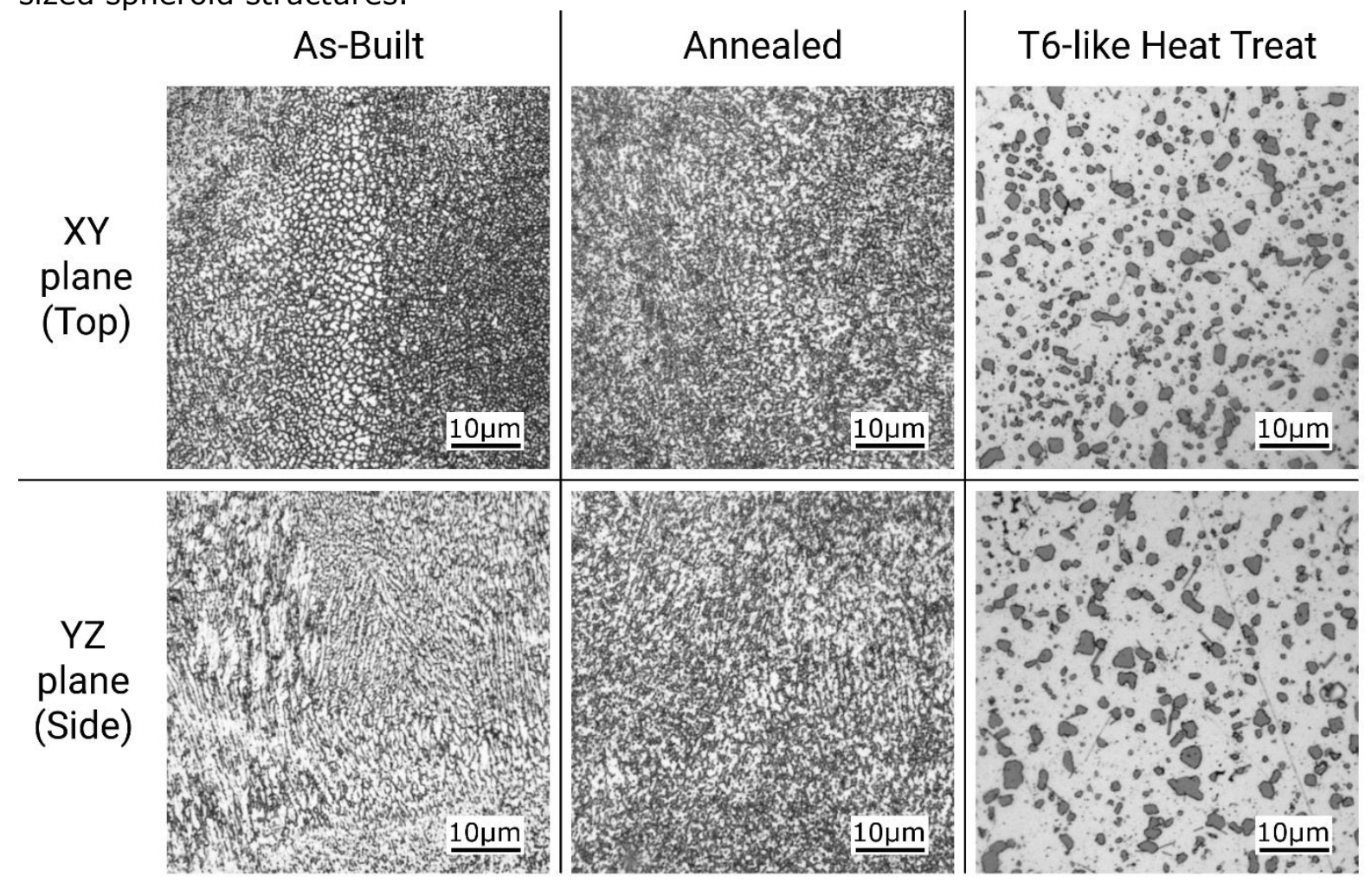

Figure 4: Optical micrographs of the $5 \mathrm{~mm}$ test cubes after being etched by Keller's reagent showing grain structure. Silicon-rich areas are seen as dark features, with aluminium areas being shown as lighter regions.

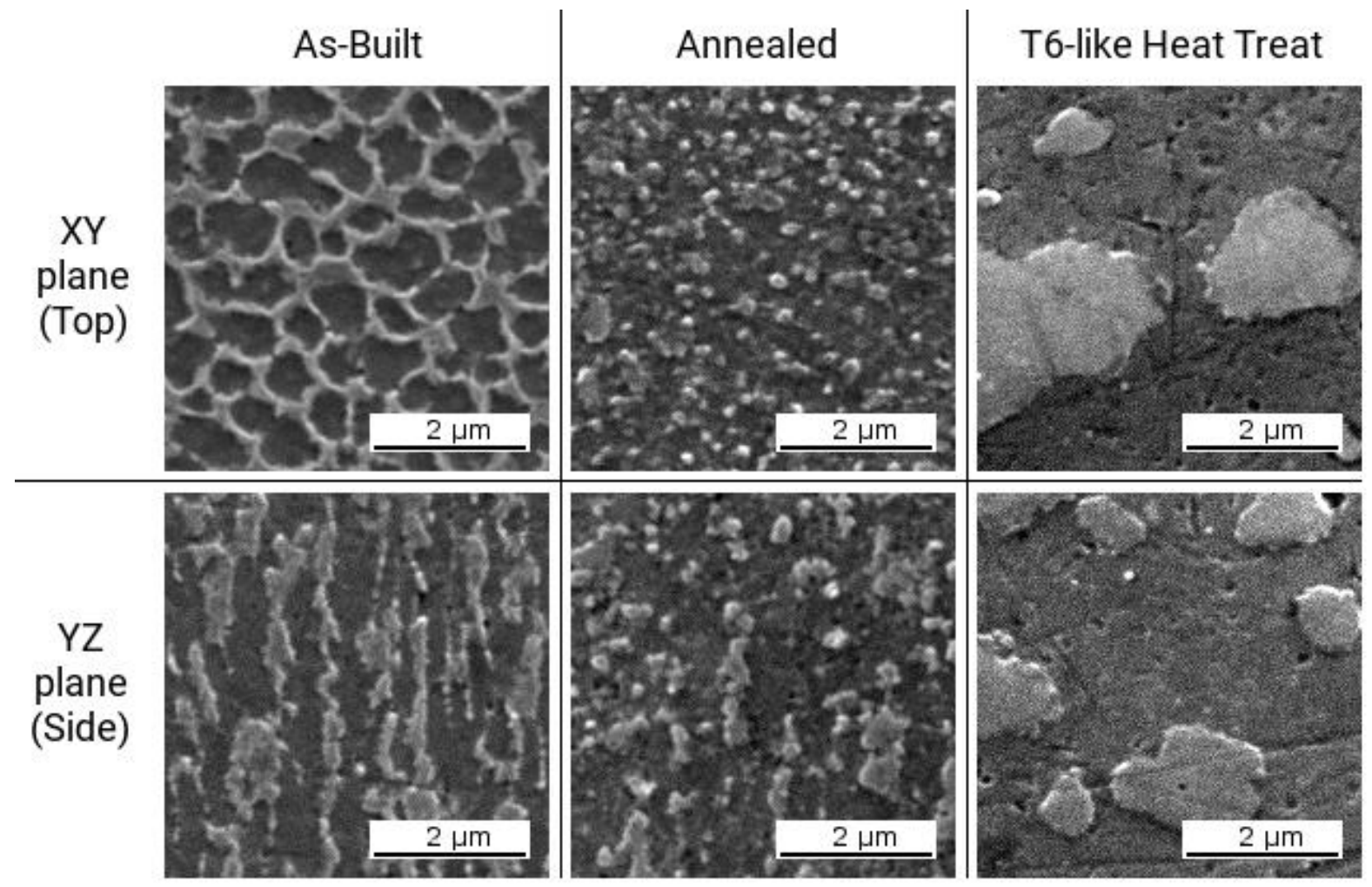

Figure 5: SEM images of the etched $5 \mathrm{~mm}$ test cubes showing close-up grain structure. Silicon-rich areas are seen as light features, with aluminium areas being shown as darker regions. 
EDX was used to reveal silicon-rich areas, as seen in Figure 6, and determine the elemental composition of the areas imaged. Silicon-rich features were seen in SEM imaging as lighter compared to the darker aluminium. As-built samples showed clear regions of highly concentrated silicon at the boundaries of the grains. The annealing process breaks these silicon-rich areas up into smaller spheroids. The T6-like heat treatment results in agglomeration of these spheroids into larger silicon-rich regions. Despite the microstructure changes, the elemental composition of the samples remained consistent, so any changes in resistivity are not due to changes in the composition of the alloy.

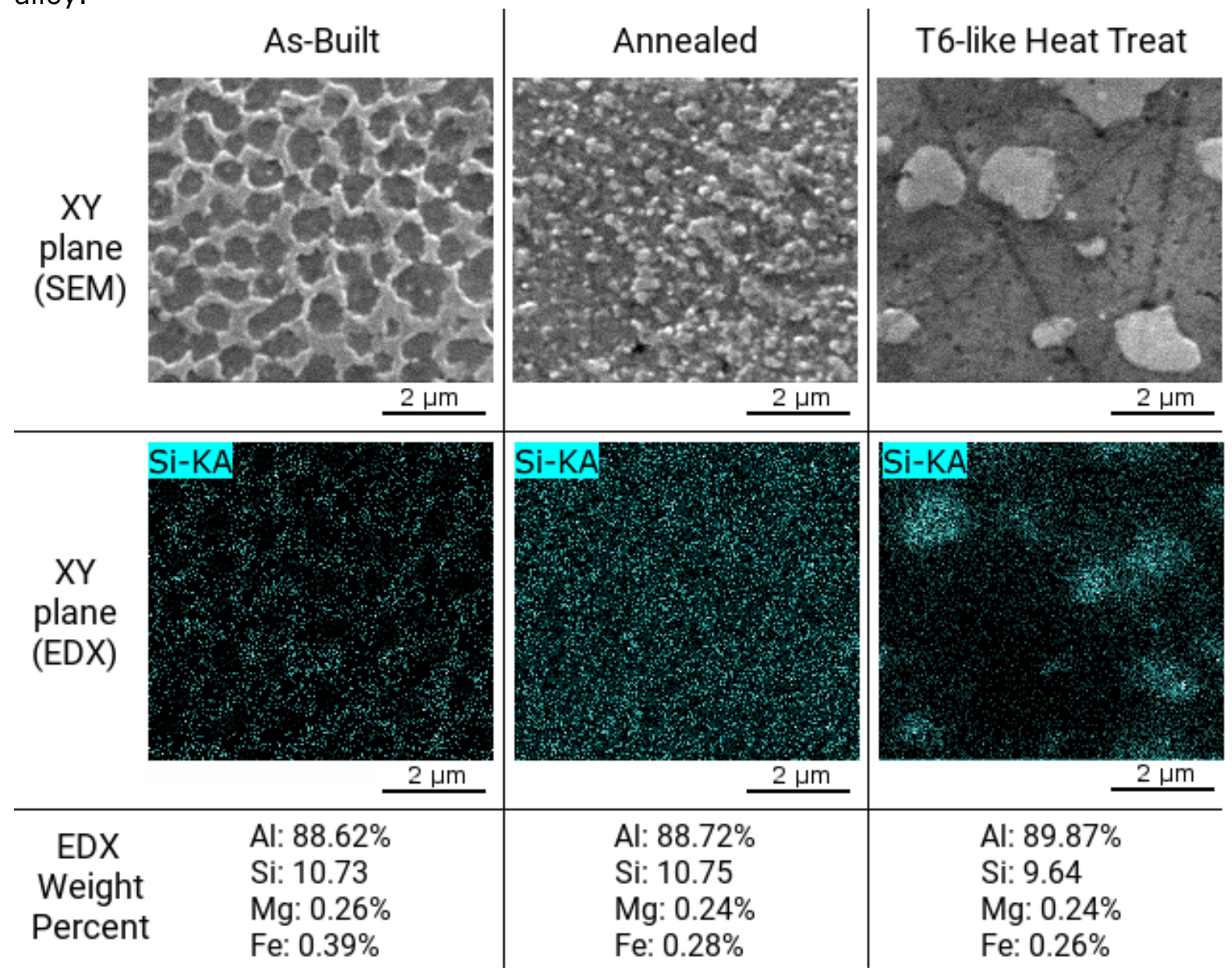

Figure 6: SEM images of the etched $5 \mathrm{~mm}$ test cubes with corresponding silicon elemental mapping and overall elemental composition expressed as a weight percentage.

\subsection{Mechanical Properties}

To determine the hardness of the test samples relative to the various conditions, the results from the nanoindentations performed were compared as shown in Figure 7. It was found that the average hardness of the as-built samples was $1.54 \mathrm{GPa}$, annealed was $1.16 \mathrm{GPa}$ and T6-like heat treatment was $1.39 \mathrm{GPa}$. These values match the trend reported by Aboulkhair[68] and suggest that these post heat treatments are predictable processes that can be applied to AISi10Mg AM parts. 


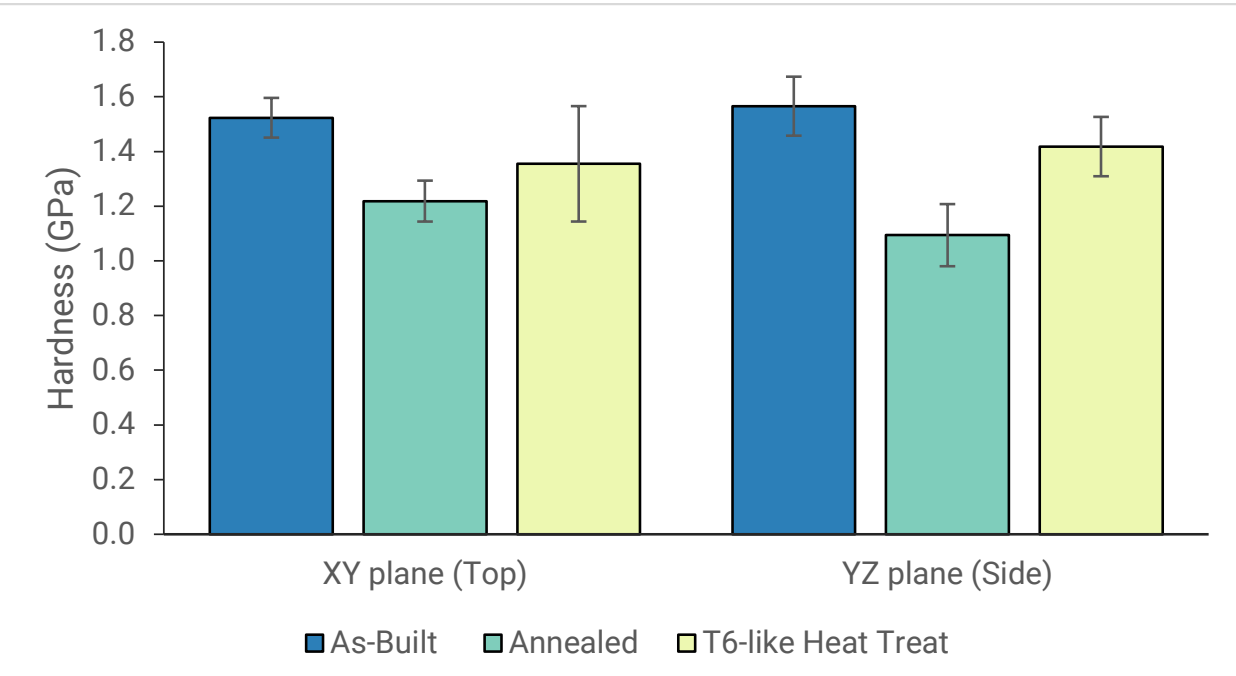

Figure 7: Nanoindentation hardness of $5 \mathrm{~mm}$ test cubes with corresponding standard deviation.

\subsection{Electrical Properties}

To determine the DC electrical resistivity of the test bars, each sample was measured five times using a digital micro-ohmmeter with results being averaged and the corresponding standard deviation calculated. In the as-built samples, the range of values for each sample varied much greater than that of the annealed or T6-like heat treated samples, as noted in the standard deviation seen in Figure 8 . Both the annealed samples and T6-like heat treated samples showed no correlation between orientation and resistivity and were relatively similar to each other in terms of resistivity, with the average annealed resistivity being $5.943 \mu \Omega-\mathrm{cm}$ and the average T6-like heat treated samples being $5.940 \mu \Omega-\mathrm{cm}$. However, the as-built samples showed a strong trend correlating resistivity and orientation. Among as-built samples, ones built vertically showed a lower resistivity with an average of $7.78 \mu \Omega-\mathrm{cm}$, with horizontal samples being the highest in the group at an average of $9.87 \mu \Omega-\mathrm{cm}$, with 45 degrees in between the two at $9.01 \mu \Omega-\mathrm{cm}$. The average of the as-built samples was $8.88 \mu \Omega-\mathrm{cm}$. This indicates that the microstructure found in the as-built samples created anisotropic electrical resistivity and contributed to the difference found in both annealed and T6-like samples.

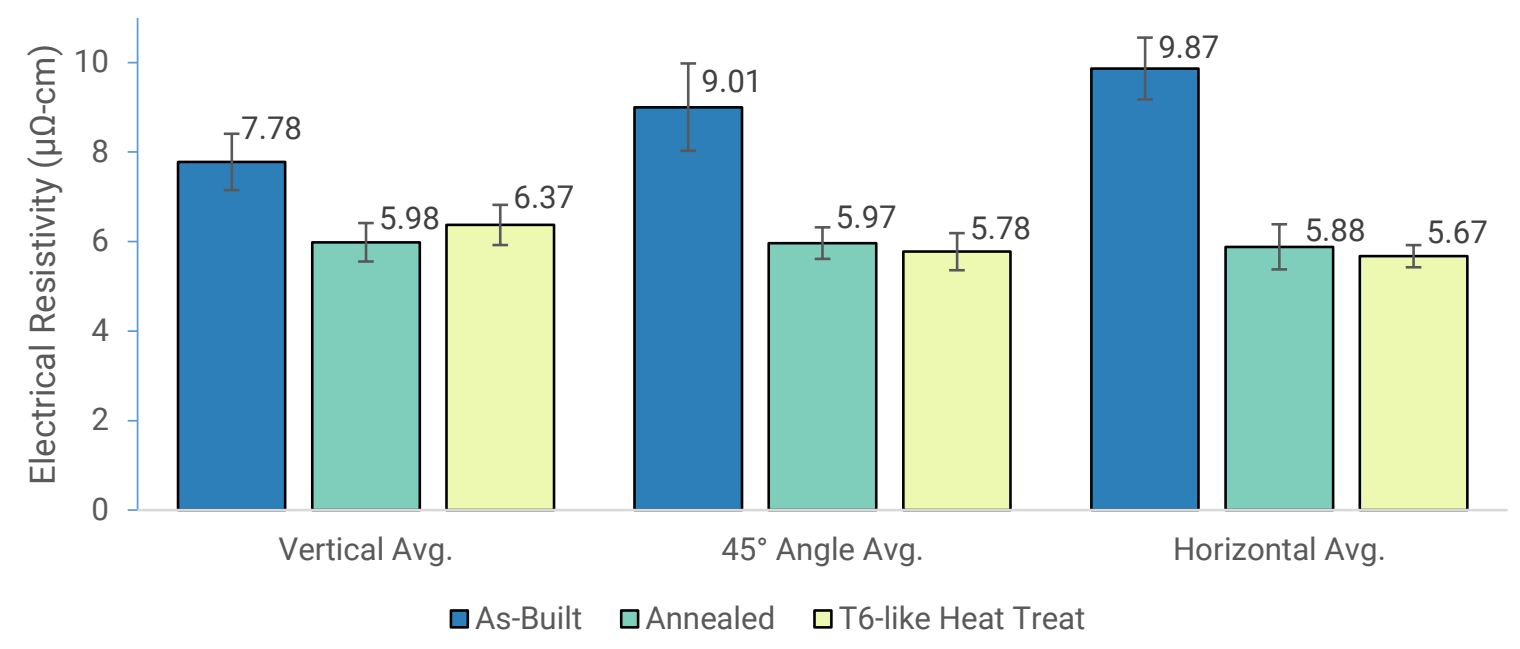

Figure 8: Averaged electrical resistivity of test bars under tested conditions with calculated standard deviations.

\section{Discussion}

Electrical resistance in solid conductors is due to a disruption to the periodic lattice structure found in the material at the atomic scale[45]. This disruption could be due to imperfections in the crystal lattice (grain boundaries, vacancies, dislocations), or from 
foreign elements occupying spaces in the lattice (impurities). In the case of alloyed metals with a secondary element comprising more than $5 \%$ of the total concentration, the impurity resistivity is the dominant form of electrical resistivity[45]. However, when the impurities are no longer randomly distributed but form their own ordered state, the resistivity can no longer be easily estimated or calculated through derived equations. In such cases, further analysis is needed to fully understand the materials electrical properties. A potential result of this ordered state is that the material no longer acts in an isotropic manner. Ohms law is typically written as $I=V / R$ where $I$ is the applied current to the sample, $V$ is the voltage drop across the sample and $R$ is the resistance of the sample. However, this law can also be written as $J=\sigma E$ where $J$ is the current density, $\sigma$ is the materials electrical conductivity and $E$ is the static electromagnetic field in the sample. This refined model is tensor-based and allows for $\sigma$ to be expressed as either a $2 \times 2$ or $3 \times 3$ matrix for anisotropic materials[71]. To fully determine this matrix, a characterisation of the structure of each phase as well as the interphase boundaries would be needed[72]. This anisotropicity is the situation that exists in the as-built SLM samples due to the rapid cooling of the SLM process which is in the order of $10^{6} \mathrm{~K} / \mathrm{s}[73]$. Other materials processed by pulsed laser deposition have also seen anisotropic electrical resistivity[74].

This rapid cooling rate results in a unique grain growth and microstructure compared to the cast version of the AISi $10 \mathrm{Mg}$ alloy, as previously reported $[63,75,76]$. Initially, a-Al solidifies into needle-like grains oriented towards the heat source (primarily in the $Z$ built direction). As it solidifies, it rejects $S i$ into the remaining liquid, which cools and leaves a saturated Si-rich structure surrounding these Al-rich cores which defines the cellular boundaries seen in Figure 5 . Three slightly different grain structures can be seen in the as-built samples; a finely grained melt pool core, a coarser boundary of the melt pool, and a disordered heat affected zone (HAZ) around the melt pool boundary[69]. Both the coarse and fine structures are elongated in the build direction and are surrounded by Si structures. HAZ areas show more fragmented Si structures due to the reheating that occurs from overlapping laser scan patterns. The annealing process breaks up these Si structures into small spherical particles[61]. The T6-like heat treatment further diffuses Si into the main a-Al areas[67] and precipitates $\mathrm{Si}$ into larger particles. Thus both the annealing process and T6-like treatments result in the breaking down of the original as-built ordered Si structures.

The difference between resistivity in the as-built samples to annealed and T6-like heat treated samples indicates that microstructure is the cause of the differences in electrical properties. As all samples were built at the same time, using the same processes, using the same test equipment, with similar elemental composition and densities, allowing only post heat treatment and corresponding microstructure to account for the difference, all other variables having been eliminated. The relatively high and consistent density of the samples seen in Table 3 cannot account for the differences in resistivity as a correlation between porosity of SLM parts with electrical conductivity has recently been shown as a linear relationship[77] with high porosity contributing to higher resistivity. Tang[61] also reported a correlation between Si microstructures and electrical conductivity of as-built and annealed samples despite using a measurement setup which assumed isotropic properties.

These Si structures create the varied nature of the as-built orientation differences in resistivity. As seen in Figure 5, the $\mathrm{Si}$ is patterned in a network of cellular structures in the $X Y$ plane compared to the elongated dendritic structures in the $Y Z$ plane. The result is a-Al concentrated in elongated needle-like shapes which align generally with the $Z$ build direction. In this study, the vertical built samples have electricity passed into the $X Y$ plane in the build direction. Since the electricity passing into the XY plane is able to travel mostly in these concentrated elongated a-Al areas, the number of times it crosses the $\mathrm{Si}$ structures is minimized. As Si is a much inferior electrical conductor than Al (and acts as an insulator at room temperature)[45], electricity that passes through fewer $\mathrm{Si}$ structures will have a lower resistivity. Here this is seen in the lower resistivity of the vertical samples compared to the horizontal ones. 
The breaking up of these segregated Si structures is the key to the lower resistivity found in the annealed and T6 samples. Even though this annealing process is sometimes referred to as a "stress relief" by some equipment manufacturers, a true stress relief should not alter grain structure which is not the case by this process and should be reclassified as annealing which does also perform a stress relief. As the performed heat treatments break down the Si-rich structures, electrons can find better pathways to flow through the Al material avoiding having to pass through these solid $\mathrm{Si}$ structures. Thus the annealed resistivity is equivalent to the T6-like heat treatment due to the breakdown of the original Si-rich structures even though the final grain structures are different from one another.

The resistivity in the results is slightly higher than literature values for this alloy. This difference could be the result of the tested heat treatments and corresponding grain structure as compared to cast versions. Generally, applying a T6 type heat treatment increases resistivity compared to the annealed version of a cast alloy. But since traditional manufacturing processes have a drastically different starting grain structure than AM, a more refined annealing process may be needed beyond the typical anneal to minimize resistivity. Therefore the values reported in these tests may not represent the lowest possible resistivity that can be achieved with this alloy.

While this alloy has not been used in electrical design applications traditionally, the number of additively manufactured aluminium alloys are limited. By providing the resistivity of this alloy, the potential for it to be used either directly in electrical applications or as a starting point for new lower resistivity AM alloys can begin. The AM design freedom can allow electrical designers to use the material properties of this alloy in new and creative ways that overcome the limitations of the material resistivity.

\section{Conclusions}

In this study, the resistivity of test specimens that were built from the aluminium alloy AlSi10Mg using additive manufacturing was measured. These test specimens were built in either a vertical, horizontal, or 45 -degree orientation. They were then either left in an as-built condition or were annealed or treated with a T6-like heat treatment. The samples were at least $99.72 \%$ dense. This high density would allow all samples to have any resistivity differences to be accounted for by different grain structures. It was found that the resulting grain structures did, in fact, create different resistivity.

As-built samples have concentrated elongated a-Al structures that are elongated along the $Z$ build direction. At the boundary of these structures is a silicon-rich area segregating each of these structures from each other. Electricity is able to pass easier through aluminium than silicon, thus the more times it needs to pass through silicon, the higher the resistivity. As-built samples show solidly defined Si-rich structures, whereas annealing breaks up these structures and the T6-like heat treatment provides a coarsening of the Si-rich regions.

The resistivity of as-built samples showed a trend of lower resistivity for vertically built samples, and higher resistivity for horizontal samples. This agrees with the premise where the current in vertical samples passes through more connected aluminium structures and the current in horizontal samples passes through more Si-rich areas. Both annealed and T6-like heat treated samples showed no correlation between build direction and resistivity. Both also showed approximately equal values for resistivity at an average of $5.94 \mu \Omega-\mathrm{cm}$ which is slightly higher, but comparable, to known resistivity values for this alloy. Therefore, the use of AM to create electrical based designs leads to little penalty in higher resistivity once an appropriate heat treatment is applied.

This is the first study to directly measure the electrical resistivity of AISi $10 \mathrm{Mg}$ and correlate the effect of additive manufacturing initial build orientation to post heat treatments. As such it opens up a new area of research for electrical design by making use of additive manufacturing as a new manufacturing technique. It allows new electrical 
component designs that can make use of the freedom AM allows over traditional manufacturing methods. This could be especially useful in designing coils for electric motors, novel antenna designs, or other electromagnetic devices.

\section{Acknowledgements}

The authors would like to acknowledge the support from Martin Roe and the Nanoscale and Microscale Research Centre (NMRC, University of Nottingham, UK) for use of their SEM and EDX equipment, as well as the support received from the technicians of the Centre for Additive Manufacturing (CfAM, University of Nottingham, UK) Mark East, Mark Hardy and Joe White, Ian Maskery for his work in etching samples, and also to Christopher Fox, who assisted with nanoindentation measurements. This research did not receive any specific grant from funding agencies in the public, commercial, or not-forprofit sectors.

\section{References}

[1] N. Hopkinson, R. Hague, P.M. Dickens, Rapid Manufacturing, John Wiley \& Sons, Ltd, Chichester, UK, 2005. doi:10.1002/0470033991.

[2] G.N. Levy, R. Schindel, Overview of layer manufacturing technologies, opportunities, options and applications for rapid tooling, Proceedings of the Institution of Mechanical Engineers, Part B: Journal of Engineering Manufacture. 216 (2002) 1621-1634. doi:10.1243/095440502321016350.

[3] J.-P. Kruth, M.C. Leu, T. Nakagawa, Progress in Additive Manufacturing and Rapid Prototyping, CIRP Annals - Manufacturing Technology. 47 (1998) 525-540. doi: 10.1016/S0007-8506(07)63240-5.

[4] I. Gibson, D.W. Rosen, B. Stucker, Additive Manufacturing Technologies, Springer US, Boston, MA, 2010. doi:10.1007/978-1-4419-1120-9.

[5] A. Hughes, B. Drury, Electric motors and drives: fundamentals, types and applications, 4th ed., Newnes Press, Oxford, United Kingdom, 2013. http://cds.cern.ch/record/1599077.

[6] R.I. Jones, The More Electric Aircraft: the past and the future?, in: IEE Colloquium. Electrical Machines and Systems for the More Electric Aircraft, IEE, 1999: pp. 1-1. doi: $10.1049 /$ ic: 19990830.

[7] W. Cao, B.C. Mecrow, G.J. Atkinson, J.W. Bennett, D.J. Atkinson, Overview of electric motor technologies used for more electric aircraft (MEA), IEEE Transactions on Industrial Electronics. 59 (2012) 3523-3531. doi:10.1109/TIE.2011.2165453.

[8] E. Aguilera, J. Ramos, D. Espalin, F. Cedillos, D.W. Muse, R.B. Wicker, E. MacDonald, 3D Printing of Electro Mechanical Systems, in: Proceedings of the 24th Solid Freeform Fabrication Symposium (SFF), Austin, Texas, USA, 2013: pp. 950961. http://www.scopus.com/inward/record.url?eid=2-s2.084898415151\&partnerID $=40 \&$ md5 $=980$ ee010286f12d903c2e363386cdc9e.

[9] J. Pippuri, S. Metsä-Kortelainen, T. Lindroos, M. Savolainen, A. Jokinen, A. Revuelta, A. Pasanen, K. Ruusuvuori, 3D Printing of Soft Magnetic Cores For Electrical Machines, in: Proceedings of the 1st Annual SMACC Research Seminar 2016, Department of Mechanical Engineering and Industrial Systems, Tampere, Finland, 2016: pp. 48-51. http://smacc.fi/wp-

content/uploads/2016/10/Proceedings-of-the-1st-Annual-SMACC-reserch-Seminar2016-v4.pdf.

[10] A. Ellery, Progress towards 3D-printed mechatronic systems, in: 2016 IEEE International Conference on Industrial Technology (ICIT), IEEE, Taipei, Taiwan, 2016: pp. 1129-1133. doi:10.1109/ICIT.2016.7474913.

[11] M. Garibaldi, C. Gerada, I. Ashcroft, R. Hague, H. Morvan, M. Garibaldi, C. Gerada, I. Ashcroft, R. Hague, H. Morvan, The Impact of Additive Manufacturing on the Development of Electrical Machines for MEA Applications: A Feasibility Study, in: 3rd International Conference More Electric Aircraft (MEA 2015), MEA2015 More Electric Aircraft, Toulouse, France, 2015. https://hal.archives-ouvertes.fr/hal01178353.

[12] G. Tseng, K.I. Jyun, P. Huang, W. Lee, Application of Additive Manufacturing for Low Torque Ripple of 6 / 4 Switched Reluctance Motor, in: Proceedings of the 19th 
International Conference on Electrical Machines and Systems (ICEMS), Institute of Electrical and Electronics Engineers (IEEE), 2016: pp. 3-6.

http://ieeexplore.ieee.org/document/7837094/.

[13] S. Lammers, G. Adam, H.J. Schmid, R. Mrozek, R. Oberacker, M.J. Hoffmann, F. Quattrone, B. Ponick, Additive Manufacturing of a lightweight rotor for a permanent magnet synchronous machine, in: 2016 6th International Electric Drives Production Conference (EDPC), IEEE, Nuremberg, Germany, 2016: pp. 4145. doi:10.1109/EDPC.2016.7851312.

[14] D. Shamvedi, O.J. McCarthy, E. O'Donoghue, P. O'Leary, R. Raghavendra, 3D metal printed sierpinski gasket antenna, in: 2017 International Conference on Electromagnetics in Advanced Applications (ICEAA), IEEE, 2017: pp. 633-636. doi:10.1109/ICEAA.2017.8065326.

[15] R.A. Bahr, Y. Fang, W. Su, B. Tehrani, V. Palazzi, M.M. Tentzeris, Novel uniquely 3D printed intricate Voronoi and fractal 3D antennas, in: 2017 IEEE MTT-S International Microwave Symposium (IMS), IEEE, 2017: pp. 1583-1586. doi:10.1109/MWSYM.2017.8058934.

[16] R. Sorrentino, O.A. Peverini, Additive manufacturing: a key enabling technology for next-generation microwave and millimeter-wave systems [point of view], Proceedings of the IEEE. 104 (2016) 1362-1366.

doi:10.1109/JPROC.2016.2577327.

[17] M. Hollenbeck, R. Smith, C. Cathey, J. Opra, Integrated single-piece antenna feed, U.S. Patent 9,742,069, 2017.

https://patents.google.com/patent/US9742069B1/en.

[18] A. Panesar, D. Brackett, I. Ashcroft, R. Wildman, R. Hague, Design Framework for Multifunctional Additive Manufacturing: Placement and Routing of ThreeDimensional Printed Circuit Volumes, Journal of Mechanical Design. 137 (2015) 111414. doi:10.1115/1.4030996.

[19] A. Aremu, I. Ashcroft, R. Wildman, R. Hague, C. Tuck, D. Brackett, The effects of bidirectional evolutionary structural optimization parameters on an industrial designed component for additive manufacture, Proceedings of the Institution of Mechanical Engineers, Part B: Journal of Engineering Manufacture. 227 (2013) 794-807. doi:10.1177/0954405412463857.

[20] M. Abdi, R. Wildman, I. Ashcroft, Evolutionary topology optimization using the extended finite element method and isolines, Engineering Optimization. 46 (2014) 628-647. doi:10.1080/0305215X.2013.791815.

[21] I. Gibson, D.W. Rosen, B. Stucker, Design for Additive Manufacturing, in: Additive Manufacturing Technologies: Rapid Prototyping to Direct Digital Manufacturing, Springer US, Boston, MA, 2010: pp. 299-332. doi:10.1007/978-1-4419-11209_11.

[22] M. Leary, L. Merli, F. Torti, M. Mazur, M. Brandt, Optimal topology for additive manufacture: A method for enabling additive manufacture of support-free optimal structures, Materials and Design. 63 (2014) 678-690. doi:10.1016/j.matdes.2014.06.015.

[23] R. Ponche, J.Y. Hascoet, O. Kerbrat, P. Mognol, A new global approach to design for additive manufacturing, Virtual and Physical Prototyping. 7 (2012) 93-105. doi: $10.1080 / 17452759.2012 .679499$.

[24] R. Ranjan, J. Tangudu, Thermal design of high power-density additivelymanufactured induction motors, in: 2014 IEEE Energy Conversion Congress and Exposition (ECCE), IEEE, 2014: pp. 1325-1331. doi:10.1109/ECCE.2014.6953554.

[25] J. Waterman, A. Clucas, T.B. Costa, Y. Zhang, J. Zhang, Numerical modeling of 3D printed electric machines, in: 2015 IEEE International Electric Machines \& Drives Conference (IEMDC), Institute of Electrical and Electronics Engineers (IEEE), Coeur d'Alene, Idaho, USA, 2015: pp. 1286-1291. doi:10.1109/IEMDC.2015.7409227.

[26] H.-S. Hong, H.-C. Liu, G.-C. Jeong, J. Lee, Design of high-end SynRM based on 3D printing technology, in: 2016 IEEE Conference on Electromagnetic Field Computation (CEFC), IEEE, 2016: pp. 1-1. doi:10.1109/CEFC.2016.7816043.

[27] M. Garibaldi, I. Ashcroft, N. Hillier, S.A.C. Harmon, R. Hague, Relationship between laser energy input, microstructures and magnetic properties of selective laser melted Fe-6.9\%wt Si soft magnets, Materials Characterization. (2018) 0-1. 
doi: 10.1016/j.matchar.2018.01.016.

[28] M. Garibaldi, I. Ashcroft, J.N. Lemke, M. Simonelli, R. Hague, Effect of annealing on the microstructure and magnetic properties of soft magnetic Fe-Si produced via laser additive manufacturing, Scripta Materialia. 142 (2018) 121-125. doi: 10.1016/j.scriptamat.2017.08.042.

[29] B.W. An, K. Kim, H. Lee, S.-Y. Kim, Y. Shim, D.-Y. Lee, J.Y. Song, J.-U. Park, HighResolution Printing of 3D Structures Using an Electrohydrodynamic Inkjet with Multiple Functional Inks, Advanced Materials. 27 (2015) 4322-4328. doi:10.1002/adma.201502092.

[30] J. Vaithilingam, M. Simonelli, E. Saleh, N. Senin, R.D. Wildman, R.J.M. Hague, R.K. Leach, C.J. Tuck, Combined Inkjet Printing and Infrared Sintering of Silver Nanoparticles using a Swathe-by-Swathe and Layer-by-Layer Approach for 3Dimensional Structures, ACS Applied Materials \& Interfaces. 9 (2017) 6560-6570. doi:10.1021/acsami.6b14787.

[31] W. Li, D. Hu, L. Li, C. Li, J. Jiu, C. Chen, T. Ishina, T. Sugahara, K. Suganuma, Printable and flexible copper-silver alloy electrodes with high conductivity and ultrahigh oxidation resistance, ACS Applied Materials \& Interfaces. (2017) acsami.7b05308. doi:10.1021/acsami.7b05308.

[32] X. Zhou, W. Li, M. Wu, S. Tang, D. Liu, Enhanced dispersibility and dispersion stability of dodecylamine-protected silver nanoparticles by dodecanethiol for ink-jet conductive inks, Applied Surface Science. 292 (2014) 537-543. doi:10.1016/j.apsusc.2013.12.006.

[33] B.K. Park, D. Kim, S. Jeong, J. Moon, J.S. Kim, Direct writing of copper conductive patterns by ink-jet printing, Thin Solid Films. 515 (2007) 7706-7711. doi: $10.1016 /$ j.tsf.2006.11.142.

[34] R.A. Matula, Electrical resistivity of copper, gold, palladium, and silver, Journal of Physical and Chemical Reference Data. 8 (1979) 1147-1298. doi: $10.1063 / 1.555614$.

[35] ASTM B193-02(2014), Standard Test Method for Resistivity of Electrical Conductor Materials, ASTM International, West Conshohocken, Pennsylvania, USA, 2014. doi:10.1520/B0193.

[36] Copper Development Association, Copper Casting Alloys, Copper Development Association Inc., New York, New York, USA, 1994. http://www.worldcat.org/title/copper-castingalloys/oclc/31469090\&referer=brief_results.

[37] W.P. Davey, Precision Measurements of the Lattice Constants of Twelve Common Metals, Physical Review. 25 (1925) 753-761. doi:10.1103/PhysRev.25.753.

[38] D.L. Ellis, D.J. Keller, Thermophysical Properties of GRCop-84, Cleveland, OH United States, 2000. https://ntrs.nasa.gov/search.jsp?R=20000064095.

[39] J.R. Davis, ASM Specialty Handbook: Aluminum and Aluminum Alloys, ASM International, 1993. https://books.google.co.uk/books?id=Lskj5k3PSIcC.

[40] L. Kirkpatrick, Aluminum Association, Aluminum electrical conductor handbook, 3rd ed., Aluminum Association, Washington, D.C., USA, 1989.

http://www.worldcat.org/title/aluminum-electrical-conductorhandbook/oclc/8839627\&referer=brief_results.

[41] R. Brandt, G. Neuer, Electrical Resistivity and Thermal Conductivity of Pure Aluminum and Aluminum Alloys up to and above the Melting Temperature, International Journal of Thermophysics. 28 (2007) 1429-1446. doi: 10.1007/s10765-006-0144-0.

[42] P. Uliasz, T. Knych, M. Piwowarska, J. Wiecheć, The Influence of Heat Treatment Parameters on the Electrical Conductivity of AISi7Mg and AISi10Mg Aluminum Cast Alloys, in: ICAA13: 13th International Conference on Aluminum Alloys, John Wiley \& Sons, Inc., Hoboken, NJ, USA, 2012: pp. 129-135. doi: $10.1002 / 9781118495292 . c h 20$.

[43] P. Frigola, O.A. Harrysson, T.J. Horn, H.A. West, R.L. Aman, J.M. Rigsbee, D.A. Ramirez, F. Medina, R.B. Wicker, E. Rodriguez, Fabricating Copper Components with Electron Beam Melting, Advanced Materials and Processes. (2014). https://www.researchgate.net/publication/283928493_Fabricating_Copper_Compo nents_with_Electron_Beam_Melting. 
[44] S.J. Raab, R. Guschlbauer, M.A. Lodes, C. Körner, Thermal and Electrical Conductivity of 99.9\% Pure Copper Processed via Selective Electron Beam Melting, Advanced Engineering Materials. 18 (2016) 1661-1666. doi: 10.1002/adem.201600078.

[45] G.T. Dyos, The Handbook of Electrical Resistivity: New materials and pressure effects, The Institution of Engineering and Technology, London, 2012. doi: 10.1049/PBED013E.

[46] S.R. Pogson, P. Fox, C.J. Sutcliffe, W. O'Neill, The production of copper parts using DMLR, Rapid Prototyping Journal. 9 (2003) 334-343. doi: $10.1108 / 13552540310502239$.

[47] P.R. Gradl, C. Protz, S.E. Greene, D. Ellis, B. Lerch, I. Locci, Development and Hotfire Testing of Additively Manufactured Copper Combustion Chambers for Liquid Rocket Engine Applications, in: 53rd AIAA/SAE/ASEE Joint Propulsion Conference, American Institute of Aeronautics and Astronautics, Reston, Virginia, 2017. doi: $10.2514 / 6.2017-4670$.

[48] M. Fateri, A. Gebhardt, J.-S. Hötter, M. Knothe, F.M. Schmidt, H. Rieper, Numerical and Experimental Investigation of Selective Laser Melting of Silver, in: Fraunhofer Direct Digital Manufacturing Conference (DDMC 2012), Berlin, Germany, 2012. https://www.researchgate.net/publication/264548342.

[49] M. Khan, P.M. Dickens, Selective Laser Melting (SLM) of pure gold, Gold Bulletin. 43 (2010) 114-121. doi:10.1007/BF03214976.

[50] E. Louvis, P. Fox, C.J. Sutcliffe, Selective laser melting of aluminium components, Journal of Materials Processing Technology. 211 (2011) 275-284. doi: 10.1016/j.jmatprotec.2010.09.019.

[51] P.A. Lykov, E.V. Safonov, A.M. Akhmedianov, Selective Laser Melting of Copper, Materials Science Forum. 843 (2016) 284-288. doi:10.4028/www.scientific.net/MSF.843.284.

[52] D. Becker, W. Meiners, K. Wissenbach, Additive manufacturing of copper alloys by selective laser melting, in: WLT - German Scientific Laser Societey (Ed.), Proceedings of the 5th International WLT-Conference on Lasers in Manufacturing (LiM2009), Munich, Germany, 2009: pp. 195-200. http://www.wlt.de/lim/LiM2009_Abstracts.pdf.

[53] J.-P. Kruth, X. Wang, T. Laoui, L. Froyen, Lasers and materials in selective laser sintering, Assembly Automation. 23 (2003) 357-371. doi: $10.1108 / 01445150310698652$.

[54] T. Kimura, T. Nakamoto, M. Mizuno, H. Araki, Effect of silicon content on densification, mechanical and thermal properties of Al-xSi binary alloys fabricated using selective laser melting, Materials Science and Engineering: A. (2016). doi:10.1016/j.msea.2016.11.059.

[55] J.D. Widmer, C.M. Spargo, G.J. Atkinson, B.C. Mecrow, Solar Plane Propulsion Motors With Precompressed Aluminum Stator Windings, IEEE Transactions on Energy Conversion. 29 (2014) 681-688. doi:10.1109/TEC.2014.2313642.

[56] J.D. Widmer, R. Martin, B.C. Mecrow, Precompressed and Stranded Aluminum Motor Windings for Traction Motors, IEEE Transactions on Industry Applications. 52 (2016) 2215-2223. doi:10.1109/TIA.2016.2528226.

[57] C.R. Sullivan, Aluminum Windings and Other Strategies forHigh-Frequency Magnetics Design in anEra of High Copper and Energy Costs, IEEE Transactions on Power Electronics. 23 (2008) 2044-2051. doi:10.1109/TPEL.2008.925434.

[58] M.C. Flemings, Solidification Processing, in: Materials Science and Technology, Wiley-VCH Verlag GmbH \& Co. KGaA, Weinheim, Germany, 2006. doi: 10.1002/9783527603978.mst0173.

[59] X. Zhao, B. Song, W. Fan, Y. Zhang, Y. Shi, Selective laser melting of carbon/AISi10Mg composites: Microstructure, mechanical and electronical properties, Journal of Alloys and Compounds. 665 (2016) 271-281. doi:10.1016/j.jallcom.2015.12.126.

[60] A. Mauduit, S. Pillot, F. Frascati, Application study of AISi10Mg alloy by selective laser melting: physical and mechanical properties, microstructure, heat treatments and manufacturing of aluminium metallic matrix composite (MMC), Metallurgical Research \& Technology. 112 (2015) 605. doi:10.1051/metal/2015039. 
[61] M. Tang, Inclusions, Porosity, and Fatigues of AlSi10Mg Parts Produced by Selective Laser Melting, Carnegie Mellon University, 2017. http://repository.cmu.edu/dissertations/903.

[62] E.O. Olakanmi, R.F. Cochrane, K.W. Dalgarno, A review on selective laser sintering/melting (SLS/SLM) of aluminium alloy powders: Processing, microstructure, and properties, Progress in Materials Science. 74 (2015) 401-477. doi:10.1016/j.pmatsci.2015.03.002.

[63] N.T. Aboulkhair, N.M. Everitt, I. Maskery, I. Ashcroft, C. Tuck, Selective laser melting of aluminum alloys, MRS Bulletin. 42 (2017) 311-319. doi: $10.1557 / \mathrm{mrs} .2017 .63$.

[64] N.T. Aboulkhair, N.M. Everitt, I. Ashcroft, C. Tuck, Reducing porosity in AISi10Mg parts processed by selective laser melting, Additive Manufacturing. 1-4 (2014) 7786. doi:10.1016/j.addma.2014.08.001.

[65] N.T. Aboulkhair, I. Maskery, C. Tuck, I. Ashcroft, N.M. Everitt, On the formation of AISi10Mg single tracks and layers in selective laser melting: Microstructure and nano-mechanical properties, Journal of Materials Processing Technology. 230 (2016) 88-98. doi:10.1016/j.jmatprotec.2015.11.016.

[66] E. Brandl, U. Heckenberger, V. Holzinger, D. Buchbinder, Additive manufactured AISi10Mg samples using Selective Laser Melting (SLM): Microstructure, high cycle fatigue, and fracture behavior, Materials \& Design. 34 (2012) 159-169. doi:10.1016/j.matdes.2011.07.067.

[67] N.T. Aboulkhair, C. Tuck, I. Ashcroft, I. Maskery, N.M. Everitt, On the Precipitation Hardening of Selective Laser Melted AISi10Mg, Metallurgical and Materials Transactions A. 46 (2015) 3337-3341. doi:10.1007/s11661-015-2980-7.

[68] N.T. Aboulkhair, I. Maskery, C. Tuck, I. Ashcroft, N.M. Everitt, The microstructure and mechanical properties of selectively laser melted AISi10Mg: The effect of a conventional T6-like heat treatment, Materials Science and Engineering: A. 667 (2016) 139-146. doi:10.1016/j.msea.2016.04.092.

[69] L. Thijs, K. Kempen, J.-P. Kruth, J. Van Humbeeck, Fine-structured aluminium products with controllable texture by selective laser melting of pre-alloyed AlSi10Mg powder, Acta Materialia. 61 (2013) 1809-1819.

doi:10.1016/j.actamat.2012.11.052.

[70] Renishaw plc., Data sheet: AlSi10Mg-0403 (200 W) powder for additive manufacturing, (2015). http://resources.renishaw.com/en/details/data-sheetalsi10mg-0403-200-w-powder-for-additive-manufacturing--73121 (accessed June $16,2017)$.

[71] M.-S. Ko, Y.-J. Kim, Resistivity Tensor Imaging via Network Discretization of Faraday's Law, SIAM Journal on Imaging Sciences. 10 (2017) 1-25. doi: $10.1137 / 16 \mathrm{M} 1074643$.

[72] P.L. Rossiter, The Electrical Resistivity of Metals and Alloys, Cambridge University Press, 1991. https://books.google.co.uk/books?id=ycj-QrSB4SQC.

[73] I. Rosenthal, A. Stern, N. Frage, Microstructure and Mechanical Properties of AlSi10Mg Parts Produced by the Laser Beam Additive Manufacturing (AM) Technology, Metallography, Microstructure, and Analysis. 3 (2014) 448-453. doi: 10.1007/s13632-014-0168-y.

[74] A.E. Espinal, Y. Yan, L. Zhang, L. Espinal, A. Morey, B.O. Wells, M. Aindow, S.L. Suib, Substrate control of anisotropic resistivity in heteroepitaxial nanostructured arrays of cryptomelane manganese oxide on strontium titanate, Small. 10 (2014) 66-72. doi:10.1002/smll.201300713.

[75] F. Trevisan, F. Calignano, M. Lorusso, J. Pakkanen, A. Aversa, E. Ambrosio, M. Lombardi, P. Fino, D. Manfredi, On the Selective Laser Melting (SLM) of the AlSi10Mg Alloy: Process, Microstructure, and Mechanical Properties, Materials. 10 (2017) 76. doi:10.3390/ma10010076.

[76] L.P. Lam, D.Q. Zhang, Z.H. Liu, C.K. Chua, Phase analysis and microstructure characterisation of AlSi10Mg parts produced by Selective Laser Melting, Virtual and Physical Prototyping. 10 (2015) 207-215. doi:10.1080/17452759.2015.1110868.

[77] Y. Shi, P. Rometsch, K. Yang, F. Palm, X. Wu, Characterisation of a novel Sc and Zr modified Al-Mg alloy fabricated by selective laser melting, Materials Letters. 196 (2017) 347-350. doi:10.1016/j.matlet.2017.03.089. 